\title{
ZM21 Magnezyum Alaşımına Lantan ve Kalsiyum İlavesinin Mikroyapı, Mekanik ve Hadde Özelliklerine Etkisi
}

\section{The Effect of Lanthane and Calcium Additional to ZM21 Magnesium Alloy on Microstructure, Mechanical and Rolling Properties}

\author{
Halil Ahmet Gören ${ }^{1 *}$, Mehmet Ünal ${ }^{2}$, Yunus Türen ${ }^{3}$, Hayrettin Ahlatç1 ${ }^{4}$ \\ Geliş / Received: 02/10/2021 \\ Revize / Revised: 01/11/2021 \\ Kabul / Accepted: 04/11/2021
}

$\underline{\text { ÖZ }}$

Bu çalışmada ZM21 Magnezyum (Mg) alaşımına La ve Ca ilavesinin döküm ve hadde sonrası mikroyapı, mekanik ve korozyon özellikleri incelenmiştir. Mikroyapı sonuçları incelendiğinde haddeleme sonrasında La ilaveli alaşımda taneler incelirken ikincil fazların bir miktar hadde yönünde uzadığı görülmüştür. Bundan farklı olarak $\mathrm{Ca}$ ilaveli alaşımda oluşan fazların haddeleme esnasında kırıldığı tespit edilmiştir. XRD sonuçlarına göre alaşımlarda $\mathrm{MgZn}, \mathrm{MgZn}_{2}, \mathrm{MgZn}_{3}, \mathrm{C} 5 \mathrm{Zn}_{3}, \mathrm{Ca}_{2} \mathrm{Mg}_{6} \mathrm{Zn}_{3}, \mathrm{LaZn}_{2}, \mathrm{LaMg}_{3}$ fazlarının oluştuğu görüldü. Daldırma korozyon özelliğine bakıldığında ZM21 Mg alaşımına kıyasla ZM21+0,5(La) Mg alaşımının hem döküm hem hadde olarak daha az ağırlık kaybı yaşanmıştır. Fakat döküm halinde ZM21+0,5(Ca) alaşımı daha düşük, haddelenmiş olarakta çok daha fazla ağırlık kaybı sergilemiştir.

Anahtar Kelimeler-Mg Alaşımları, ZM21, Döküm, Hadde

\begin{abstract}
In In this study, the microstructure, mechanical and corrosion properties of $\mathrm{La}$ and $\mathrm{Ca}$ addition to ZM21 Magnesium $(\mathrm{Mg})$ alloy after casting and rolling were investigated. When the microstructure results were examined, it was observed that the secondary phases elongated a little in the rolling direction, while the grains were thinner in the La added alloy after rolling. Differently from this, it was determined that the phases formed in the Ca-added alloy were broken during rolling. According to XRD results, it was observed that $\mathrm{MgZn}, \mathrm{MgZn}_{2}, \mathrm{MgZn}_{3}, \mathrm{C} 5 \mathrm{Zn}_{3}$, $\mathrm{Ca}_{2} \mathrm{Mg}_{6} \mathrm{Zn}_{3}, \mathrm{LaZn}_{2}, \mathrm{LaMg}_{3}$ phases were formed in the alloys. Considering the immersion corrosion property, $\mathrm{ZM} 21+0.5(\mathrm{La}) \mathrm{Mg}$ alloy experienced less weight loss in both casting and rolling compared to ZM21 Mg alloy. however, ZM21 $+0.5(\mathrm{Ca})$ alloy exhibited lower weight loss in cast form and much greater weight loss in rolled form.
\end{abstract}

\section{Keywords- Mg Alloys, ZM21, Casting, Rolling}

1*Sorumlu yazar iletişim: agoren@sinop.edu.tr (https://orcid.org/0000-0003-4455-4024)

Mekatronik Programı, Sinop Üniversitesi, Meslek Yüksek Okulu, Sinop, Türkiye

2İletişim: munal@karabuk.edu.tr (https://orcid.org/0000-0003-3836-4566)

İmalat Mühendisliği, Karabük Üniversitesi, Karabük, Türkiye

3illetişim: yturen@karabuk.edu.tr (https://orcid.org/0000-0001-8755-1865)

Metalurji ve Malzeme Mühendisliği, Karabük Üniversitesi, Karabük, Türkiye

4İletişim: hahlatci@karabuk.edu.tr (https://orcid.org/0000-0002-6766-4974)

Metalurji ve Malzeme Mühendisliği, Karabük Üniversitesi, Karabük, Türkiye 


\section{GİRIŞ}

Magnezyum mühendislik malzemesi olarak kullanılan metalik malzemelerin en hafifidir. Magnezyum alaşımları düşük yoğunluk, kolay geri dönüşüm, bol kaynak ve korozyon direnci gibi spesifik özellikleri ile bilinir [1]. Magnezyum spesifik olarak mukavemet ve işlenebilirlik gibi üstün özelliklerinden dolayı çok etkili bir malzeme olup kontrollü atmosfer altında iyi dökülebilirliğe sahiptir [2]. Mg-Zn alaşımları, orta düzeyde mukavemet ve korozyon direnci ile birlikte yüksek şekillendirilebilirlik ana avantajı ile en umut verici $\mathrm{Mg}$ alaşımları arasındadır [3]. Son zamanlarda, toksik olmayan elementler içerdiği için yüzey işlemi gerektirmeyen Mg-Zn serisi alaşımlar, implant malzemeleri olarak büyük potansiyel göstermiştir. Bununla birlikte, büyük miktarda alaşım elementinin eklenmesi, özellikle Zn içeriği ağırlıkça \% $3^{\prime}$ ten büyük olduğunda, korozyon direncinin önemli ölçüde azaldığı görülmüştür [4]. ZM21 alaşımı, biyo-uyumluluk özelliklerinden dolayı implant için en uygun aday malzemelerden biri olup [5] şekillendirilebilirlik açısından iyidir [6]. Literatürde Ca gibi elementlerin ZM21'e eklenmesi ile ilgili az sayıda çalışma bulunurken, La elementinin ZM21 Mg alaşımının haddelenebilirliği üzerindeki etkisine dair herhangi bir çalışmaya rastlanmamıştır. Bu nedenle, bu çalışma, $\mathrm{La}, \mathrm{Ca}$, katk1lı ZM21 alaşımlarının özelliklerinin hem döküm hem de haddelenmiş durumda karşılaştırmalı bir incelemesini sunmaktadır.

\section{MATERYAL VE METOT}

\section{A. Alaşımlama Metodu}

ZM21 Magnezyum alaşımlarına \% 0,5 oranında La ve Ca elementleri ilave edilmiş ve indüksiyon ocağına yüklenerek $750{ }^{\circ} \mathrm{C}$ 'ye kadar 1 ssıtılmışıır. Ergitme işlemi esnasında ortamın atmosferle temasını kesmek için koruyucu gaz olarak pota içerisinde sürekli Argon ve $\mathrm{CO}_{2}+\mathrm{SF}_{6}$ gazı akışı sağlanmıştır. Ergitme tamamlandıktan sonra Gravity yöntemi ile metal Y kalıba döküm yapılmıştır.

\section{B. Haddeleme Metodu}

Ardından döküm parçalar kalıptan çıkarılmış ve uygun bölgelerden kesilerek haddelenecek kısımlar $400{ }^{\circ} \mathrm{C} 16$ saat homojenleştirilmiştir. Böylece iç gerilmeler giderilmiştir. Sonrasında $350^{\circ} \mathrm{C}$ olarak seçilmiş haddeleme sıcaklığında ve $\% 80$ haddeleme oranı, 4,7 haddeleme hızı, Numunelere geçiş başına yaklaşık olarak $\varphi=0.2^{\prime}$ lik sabit bir deformasyon derecesi uygulanmıştır. $10 \mathrm{~mm}$ 'den $2 \mathrm{~mm}$ 'ye kadar 8 paso ile haddeleme işlemi yapılmıştır $[7,8]$.

\section{Numune Hazırlama Metodu}

Sonrasında elde edilen numunelerden döküm ve hadde olarak optik mikroskop ile metalografik inceleme yapılması için numunelerin yüzeyleri sırası ile 400, 600, 800, 1200 ve 2000 mesh zımparalar ile saf su yardımıyla zımparalanmıştır. Ardından $1 \mu \mathrm{m}$ alümina kullanılarak numunelerin yüzeyleri parlatılmış, saf su ve alkolle numunelerin yüzeyi durulanmış ardından kurutulmuştur.

\section{Mikroyapı Gözlem Metodu}

Daha sonra yüzeyi kurutulmuş numuneler pikrik asit ile dağlama işlemi yapılmış, dağlanan numuneler tekrar sırasıyla saf su, alkol ile temizlenip kurutulmuş ve Nikon marka optik mikroskopta inceleme yapılmıştır. Ardından Carl Zeiss Ultra Plus Gemini marka SEM (Taramalı Elektron Mikroskobu) cihazı ile SEM görüntüleri ve EDX analizleri alınmıştır. Döküm sonrası tüm numunelerin XRD profilleri Rigaku Ultima IV marka cihaz ile $10^{\circ}-90^{\circ}$ tarama açısı aralığında ve $3^{\circ}$ dakika tarama hızında yapılmıştır.

\section{E. Sertlik Ölçme Metodu}

Döküm, homojen ve haddeleme numunelerinin sertlikleri Vickers sertlik testi ile ölçülmüştür. Vickers sertlik testinde $0,3 \mathrm{~kg}$ yük altında piramit şekilli batıcı uç ile 15 saniye bekletilmiş ve iz çapları ölçülerek sertlik değerleri belirlenmiş̧ir.

\section{F. Çekme Test Metodu}

Döküm alaşımlarından $5 \mathrm{~mm}$ çapında ve $25 \mathrm{~mm}$ ölçü uzunluğunda köpek kemiği şeklindeki çekme numuneleri, EN ISO 6892-1'e göre işlenirken, haddelenmiş alaşımların çekme numuneleri, haddeleme yönleri boyunca ASTM E8 M-04'e göre hazırlanmıştır. Numunelere yapılan Çekme testleri Zwick/Roell Z600 çekme cihazında, $1,67 \times 10^{-3} \mathrm{~s}^{-1}$ çekme hızında ve oda sıcaklığında uygulanmıştır. Her test koşulu en az üç kez tekrarlanmıştır. 


\section{G. Daldırma Korozyon Deney Metodu}

$\% 3,5 \mathrm{NaCl}$ ile karış̧ırılmış saf su içerisinde 72 saat bekletilerek daldırma korozyon testi yapılmıştır. 3 saat ara ile numuneler kavanozlardan çıkarılarak sırasıyla saf su, kromik asit, alkol ile temizlendikten sonra ultrasonik titreşimli temizleme cihazında 10'ar dakika bekletilmiştir ve sonrasında tartılmış ardından tekrar \%3,5 $\mathrm{NaCl}$ içine konmuştur. Bu işlemler 72 saat tamamlanıncaya kadar devam etmiştir.

\section{H. Potansiyodinamik Korozyon Deney Metodu}

Potansiyodinamik polarizasyon testleri \%3,5 $\mathrm{NaCl}$ içerisinde, bilgisayar kontrollü DC105 korozyon analizine sahip Gamry model PC4/300 mA potansiyostat/galvanostat ile yapılmıştır. Deneyin yapılısında karşıt elektrot için grafit çubuk, referans elektrot için doymuş kalomel elektrot (SCE) kullanılmış ve çalışma elektrodu olarak numune yüzeyinin kullanılarak klasik üç elektrotlu hücre kullanılarak yapılmıştır. Polarizasyon eğrileri, 1 $\mathrm{mV} . \mathrm{s}^{-1}$ tarama hızında, $-0,25 \mathrm{~V}$ (vs. açık devre potansiyeli, Eoc) $+0,25 \mathrm{~V}$ (vs. Eoc) aralığında tarama ile oluşturulmuştur. Her parametre için 3 tane potansiyodinamik polarizasyon testi yapılmış ve bulunan sonuçların ortalaması alınmıştır.

\section{DENEYSEL SONUÇLAR VE TARTIŞMA}

\section{A. XRF Sonuçları}

Üretilen alaşımların döküm sonrası kimyasal bileşimleri XRF X-Işınları Floresans yöntemi ile Rigaku ZSX Primus II marka cihaz kullanılarak belirlenmiştir. Bu yöntemde floresans adı verilen her bir elemente özgü farklı dalga boylarına sahip ikincil ışımalardan faydalanarak alaşım elementlerinin ağırlık \% oranları belirlenmiştir. Alaşımların döküm sonrası yapılan XRF testleri sonucunda elde edilen kimyasal bileşimleri Tablo1.'de görülmektedir.

Tablo 1. Alaşımın kimyasal kompozisyonu

\begin{tabular}{cccccc}
\hline \multirow{2}{*}{ Alaşımlar } & \multicolumn{5}{c}{ Kimyasal Bileşim (Ağırlıkça \%) } \\
\cline { 2 - 6 } & Zn & Mn & La & Ca & Mg \\
\hline ZM21 & 2.053 & 0.512 & - & 0,031 & Kalan \\
ZM21+\%0,5 Ca & 2,192 & 1,296 & - & 0,716 & Kalan \\
ZM21+\%0,5 La & 2,027 & 1,146 & 0,679 & 0,063 & Kalan \\
\hline
\end{tabular}

\section{B. XRD Sonuçlart}

ZM21 alaşımının döküm olarak alınmış numuneden yapılan XRD testi sonuçları Şekil 1.'de verilmiştir. Alaşımların mikroyapısında $\mathrm{Mg}, \mathrm{MgZn}, \mathrm{MgZn}_{2}, \mathrm{MgZn}_{3}, \mathrm{C}_{5} \mathrm{Zn}_{3}, \mathrm{Ca}_{2} \mathrm{Mg}_{6} \mathrm{Zn}_{3}, \mathrm{LaZn}_{2}, \mathrm{LaMg}_{3}$ ikili ve üçlü fazlarının varlı̆̆ı tespit edilmiştir. Literatürdeki çalışmalar incelendiğinde çalışmamızda tespit edilen fazların benzer çalışmalarda da tespit edildiği gözlemlenmiştir [9-14].

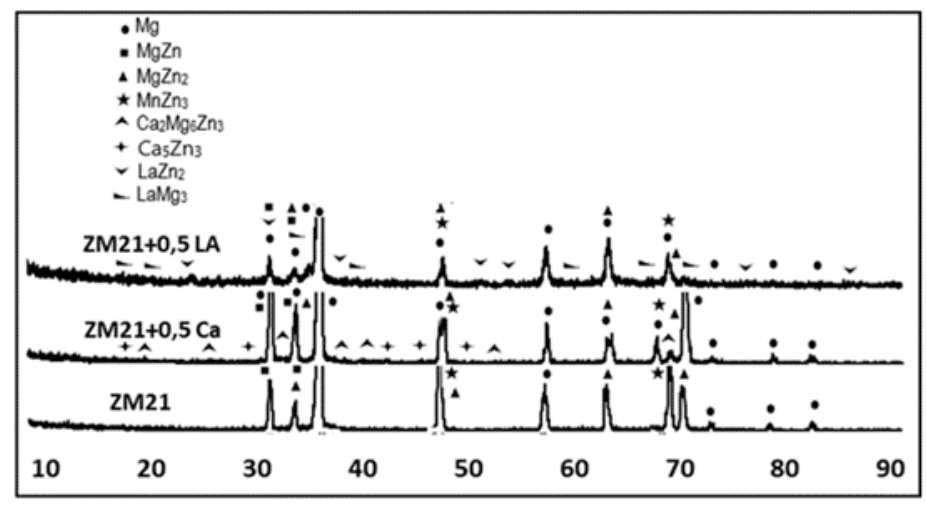

Şekil 1. ZM21 Alaşımının XRD sonuçları. 


\begin{tabular}{|c|c|c|}
\hline & $\begin{array}{l}\text { BŞEÜ Fen Bilimleri Dergisi } \\
8(2), 1024-1031,2021\end{array}$ & $\begin{array}{r}\text { BSEU Journal of Science } \\
\text { https://doi.org/10.35193/bseufbd.1003822 }\end{array}$ \\
\hline $\begin{array}{l}\text { CIKSEYHED } \\
\text { VERSIT }\end{array}$ & & 2458-7575 (https://dergipark.org.tr/tr/pub/bseufbd) \\
\hline
\end{tabular}

\section{Mikroyapı ve SEM Sonuçları}

Döküm ve haddelenmiş alaşımlara baktığımızda alaşımlardaki $\alpha$-Mg ortalama tane büyüklüğü Şekil 2.'deki mikroyapılarda görülmektedir. Dökme alaşımlarda La ilavesi ile ortalama tane büyüklügü̈, tane şekilleri ve matriste bir değişim olduğu görülmektedir. Ca ilavesi ile de tanelerde ve matriste bir değişim olmuştur. Haddelenmeden sonra tane boyutu incelmiş ve hadde yönünde kesme bantları olduğu düşünülen izler meydana geldiği görülmüştür.

Şekil 3'de verilen sem görüntüleri incelendiğinde La ilavesi ile matris içerisinde oluşan fazların haddeleme ile uzadığı görülmektedir. Ca ilaveli alaşıma baktı̆̆ımızda matris ve tane sınırlarında fazların oluştuğu görülmektedir. Haddeleme ile bu fazların kırıldığı açıkça görülmektedir. Bu duruma Ca ilavesi ile meydana gelen sertlik ve düşük akmanın neden olduğu düşünülmektedir.

Literatürdeki Mg-Zn-Mn alaşımlarının mikroyapısı ile ilgili benzer bir çalışmada farklı Zn içeriğgine sahip Mg-Zn-Mn-Ca alaşımlarının optik mikrografları gösterilmiştir. Döküm halindeki Mg-Zn-Mn-Ca alaşımlarının Zn içeriği arttıkça tane boyutunun azaldığını göstermiştir. İkincil faz, tane sınıında esas olarak şerit benzeri dağılırken, bazı tanecikli fazlar matriste bulunmuştur. Zn içeriğinin artmasıyla ikincil fazların miktarının arttığı gözlenmiştir. EDX analizleri incelenen çalışmada, tane sınırındaki ve matristeki ikincil fazların her ikisinin de Mg, $\mathrm{Zn}$ ve $\mathrm{Ca}$ elementlerinden oluştuğu belirtilmiştir [15].

Diğer bir çalışmada haddeleme sıcaklığı ve geçiş başına azalma, ZME200 alaşımının deformasyon mekanizması ve nihai mikro yapısı üzerinde büyük etkilere sahiptir. Deformasyon ikizlenmesi, daha düşük sıcaklıklarda ve daha yüksek kalınlık azalmalarında daha aktiftir ve daha ince mikro yapıya yol açar. Haddelenmiş ZME200 alaşımında oluşturulan doku, enine yöne geniş yayılıma sahip tipik bir bazal dokudur. Tavlama sırasında statik yeniden kristalleşme nedeniyle ZME200 alaşımında çift pik yayılan bazal olmayan bir doku oluştuğu bildirilmiş̧ir [16].

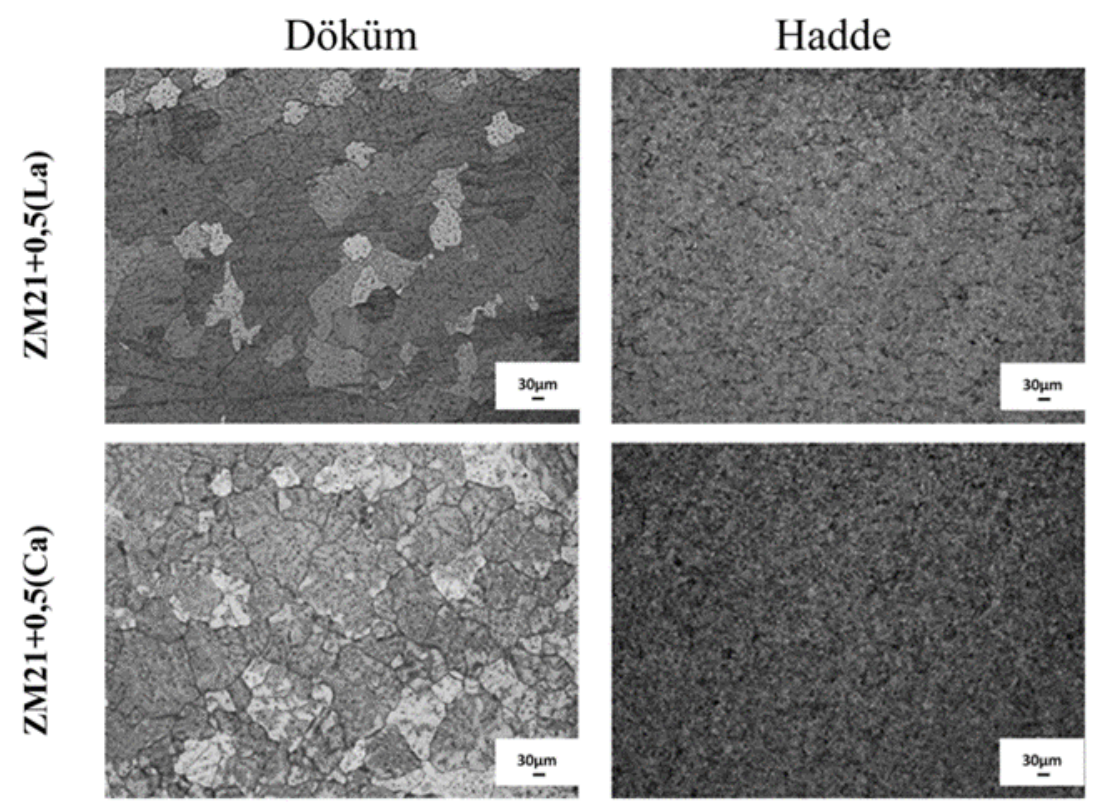

Şekil 2. ZM21 Döküm ve hadde olarak 100x mikroyapı görüntüleri 


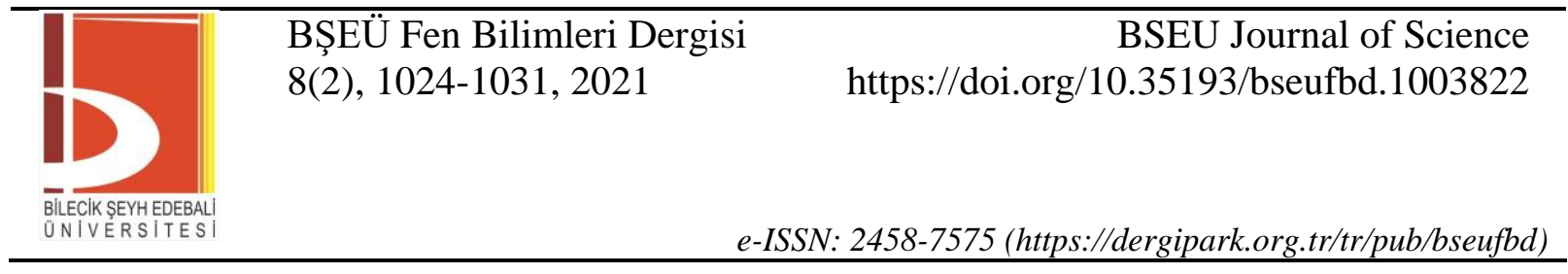
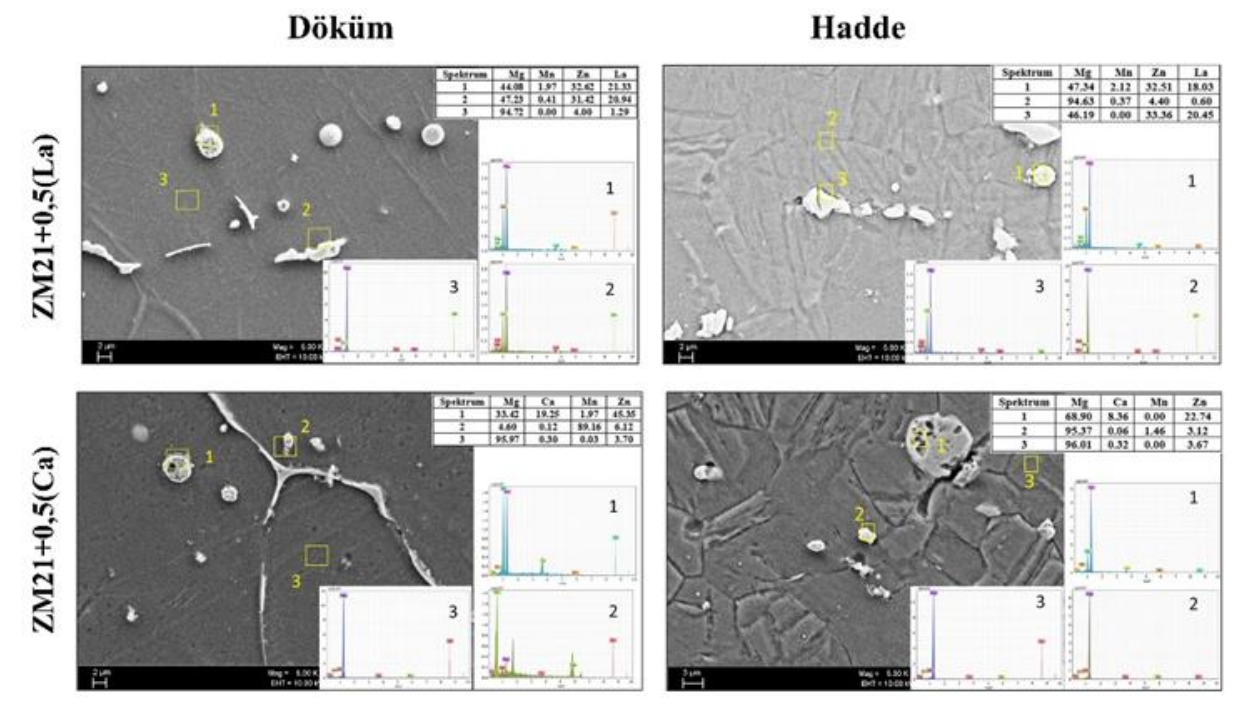

Şekil 3. Döküm ve hadde olarak SEM görüntüleri

\section{Mekanik Özellikler}

Şekil 4'teki çekme deneyi sonuçlarına baktığımızda döküm halinde incelenen alaşımlarda element ilavesi ile çekme, akma ve uzama değerleri düşmüştür. Bu durum sertliğin artması ile ilgili olduğu düşünülmektedir. Özellikle Ca ilavesi ile \% uzamanın çok alt seviyelere düşmesi, oluşan fazların sertliğini ne ölçüde arttırdığının göstergesidir. Haddelenmiş alaşımlara baktı̆ıımızda $\mathrm{Ca}$ ilaveli alaşımlar şekillendirme sırasında sertlikten dolayı parçalandığı için çekme numunesi alınamadı ve bu yüzden çekme sonucu elde edilememiştir. ZM21 ve \%0,5 La ilaveli alaşımların haddeleme için elverişli olduğu tespit edilmiştir. \% uzama değerleri de haddeleme ile yükselmiş̧ir. Çekme değeri ve \% uzamalar arasında iyi bir ilişki olduğu düşünülmektedir.
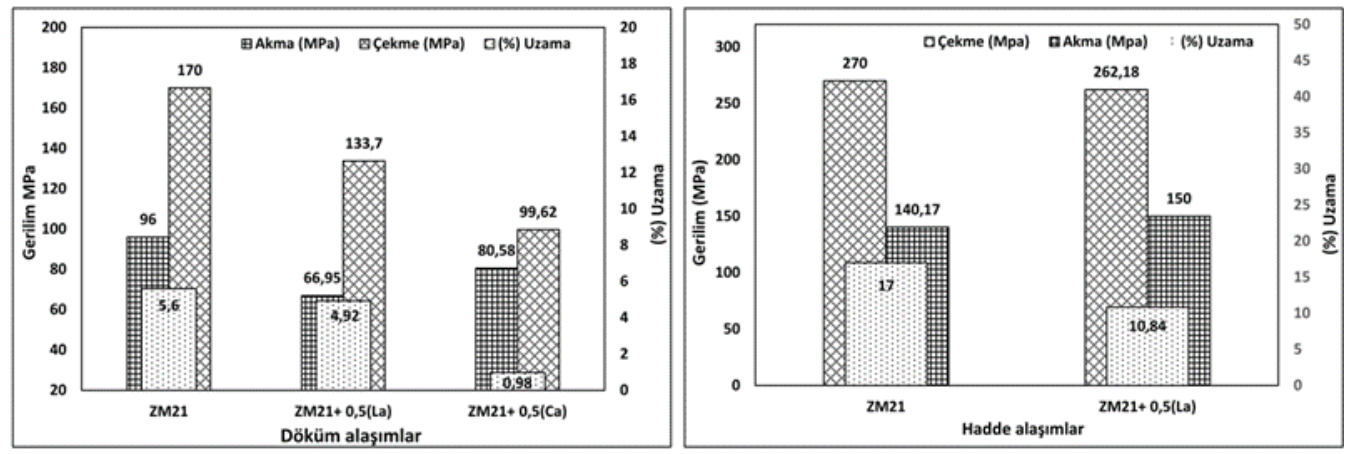

Şekil 4. Döküm ve hadde olarak Çekme, Akma, Uzama

Şekil 5'teki sertlik sonuçları incelendiğinde en yüksek sertlik değeri Ca ilaveli alaşımda ortaya çıkmıştır. Bu durum hadde esnasında kırılan parçalarda ölçüldüğünde çok yükseldiği tespit edilmiştir. Kırılmanın nedeni olarak Ca ilavesi ile yapıda oluşan fazların sertliği çok arttırması hususu olduğu düşünülmektedir. Z. H. Chen ve arkadaşları yaptıkları çalışmada yapıda oluşan bu gibi fazların katı çözelti sertleşmesi ve dağılımlı dayanımı güçlendirdiğini bildirmişlerdir [17]. 


\begin{tabular}{|c|c|c|}
\hline & $\begin{array}{l}\text { BŞEÜ Fen Bilimleri Dergisi } \\
8(2), 1024-1031,2021\end{array}$ & $\begin{array}{r}\text { BSEU Journal of Science } \\
\text { https://doi.org/10.35193/bseufbd.1003822 }\end{array}$ \\
\hline $\begin{array}{l}\text { BiLECIKSEYYHEDEBAL } \\
\text { UNIVERSITESS }\end{array}$ & & :2458-7575 (https://dergipark.org.tr/tr/pub/bseufbd) \\
\hline
\end{tabular}

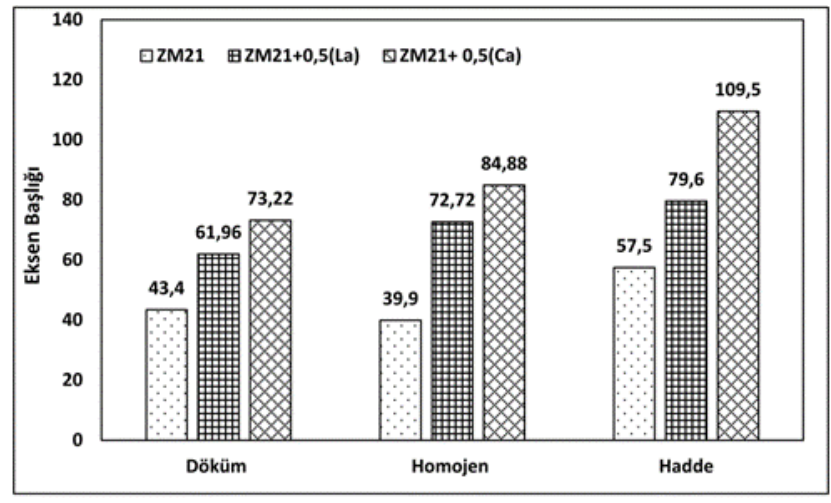

Şekil 5. Döküm, homojen ve hadde olarak \%Uzama.

\section{E. Daldırma korozyon deneyi}

Şekil 6'daki daldırma korozyon deneyi sonuçlarına baktığımızda, ZM21+0,5(La) Mg alaşımının hem döküm hem hadde olarak ZM21 Mg alaşımına kıyasla daha az ağırlık kaybı yaşadığı tespit edilmiştir. Korozyon hızlarının daha düşük olduğu görülmektedir. ZM21 Mg alaşımına oranla ZM21+0,5(Ca) alaşımı incelendiğinde döküm olarak daha düşük fakat hadde olarak çok daha fazla ağırlık kaybı yaşadığı tespit edilmiştir. Hadde ZM21+0,5(Ca) alaşımının korozyon hızı çok yüksektir fakat döküm ZM21+0,5(Ca) alaşımın korozyon hızı daha düşüktür. Hadde alaşımında Ca ilavesiyle yapıda oluşan 2'li ve 3' lü fazların haddelemenin etkisiyle kırıldığını SEM resimlerinde görüldü ve bu durumunda korozyon özellikleri üzerinde etki ettiği düşünülmektedir. Literatürdeki benzer bir çalışmada korozyon davranışı, \%3,5 $\mathrm{NaCl}$ çözeltisi içinde daldırma testleri ve potansiyodinamik polarizasyon ölçümleri ile değerlendirildi. Daldırma testleri ve potansiyodinamik polarizasyon ölçümlerinden elde edilen sonuçlarda, AZ91 alaşımının korozyon direncinin, alaşımın Ti içeriğinin artmasıyla kademeli olarak arttı̆̆ rapor edilmiştir [18].

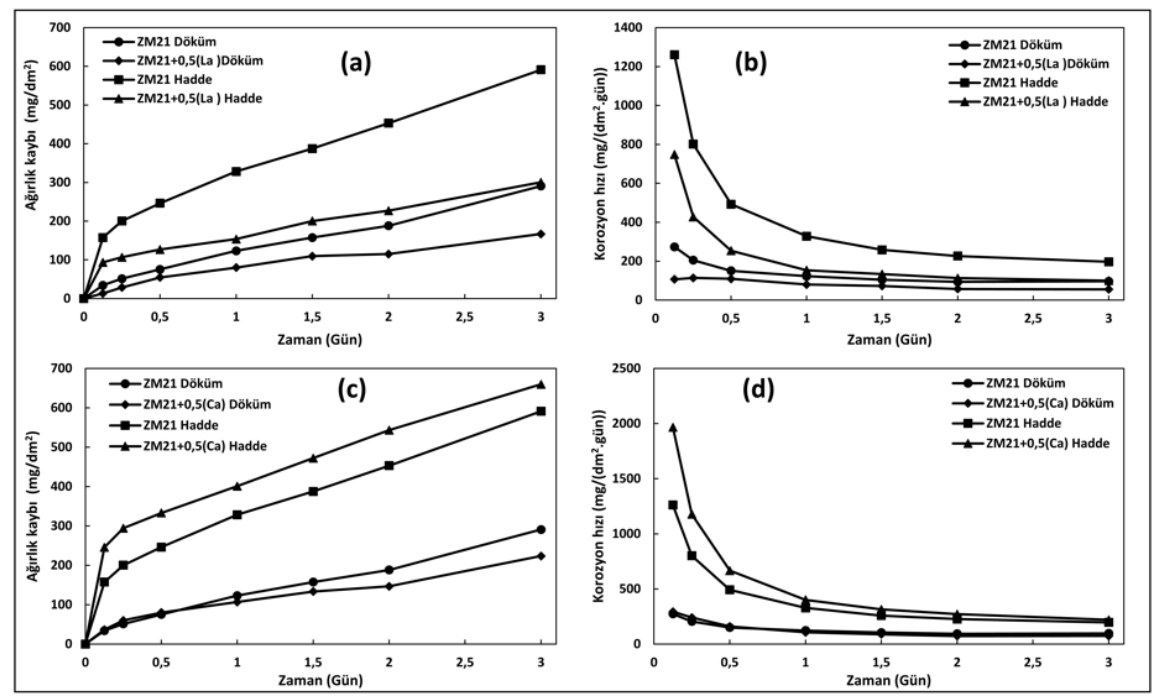

Şekil 6. ZM21 ve La ilaveli alaşımın (a) Ağırlık kaybı (b) Korozyon hızı ve ZM21 ve Ca ilaveli alaşımın (c) Ağırlık kaybı (d) Korozyon hızı.

\section{F. Potansiyodinamik korozyon deneyi}

Şekil 7. (a)'ya bakıldığında elde edilen polarizasyon eğrilerinde ZM21+0,5(La) alaşımı döküm ZM21'e göre daha negatif değerde kalmıştır. Hadde ZM21'e göre daha pozitif değerde kalmıştır. Bunlardan hesaplanan korozyon akım yoğunlukları ve korozyon potansiyelleri Şekil 8 (a)'da gösterilmektedir ve korozyon potansiyellerine bakıldığında alaşımının ZM21'e göre korozyon akım yoğunluğu azalmış ve korozyon direnci artmıştır. 


\begin{tabular}{|c|c|c|}
\hline & $\begin{array}{l}\text { BŞEÜ Fen Bilimleri Dergisi } \\
8(2), 1024-1031,2021\end{array}$ & $\begin{array}{r}\text { BSEU Journal of Science } \\
\text { https://doi.org/10.35193/bseufbd.1003822 }\end{array}$ \\
\hline $\begin{array}{l}\text { BiLECIKSEYYHEDEBAL } \\
\text { UNIVERSITESS }\end{array}$ & & :2458-7575 (https://dergipark.org.tr/tr/pub/bseufbd) \\
\hline
\end{tabular}

Şekil 7 (b) bakıldığında elde edilen polarizasyon eğrilerinde döküm ZM21+0,5(Ca) alaşımı döküm ZM21'e göre daha pozitif değerde kalmıştır. Hadde ZM21+0,5(Ca) alaşımı, hadde ZM21'e göre daha pozitif değerde kalmıştır. Bunlardan hesaplanan korozyon akım yoğunlukları ve korozyon potansiyelleri Şekil 8. (b)'de gösterilmektedir ve korozyon potansiyellerine bakıldığında döküm ZM21+0,5(Ca) alaşımının korozyon akım yoğunluğu azalmış ve korozyon direnci artmıştır. Hadde ZM21+0,5(Ca) alaşımının korozyon akım yoğunluğu artmış ve korozyon direnci düşmüştür.

Literatürdeki bir çalışmada ZM21 alaşımına Ca ilavesi ile $\alpha$-Mg matris korozyonunu engelleyen tane inceltme, $\mathrm{Ca}_{2} \mathrm{Mg}_{6} \mathrm{Zn}_{3}$ fazının oluşumu meydana gelmiş ve korozyon direnci artmıştır. Ağırlıkça \%1.6 gibi fazla $\mathrm{Ca}$ ilavesi, alaşımın hem mekanik performansını hem de korozyon direncini zayıflatan $\mathrm{Mg}_{2} \mathrm{Ca}$ fazının oluşmasına neden olduğu rapor edilmiştir [19]. Bu çalışmada da [19] döküm ZM21'e \%0,5Ca ilavesi ile elde edilen sonuçlar uyuşmaktadır.
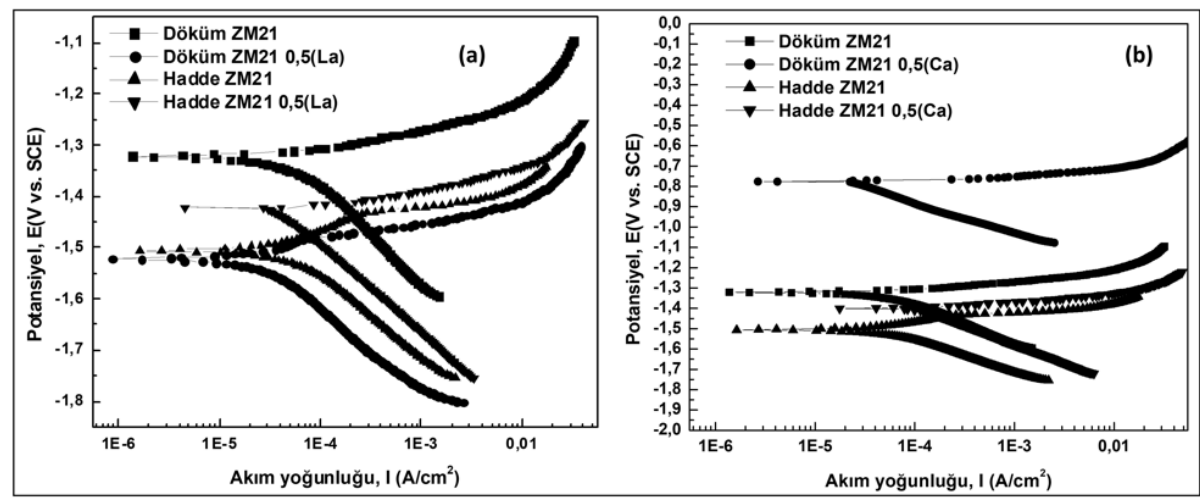

Şekil 7. ZM21 alaşımı ile karşılaştırmalı olarak (a) La ilaveli ve (b) Ca ilaveli alaşımların potansiyel ve akım yoğunlukları gösterilmektedir.

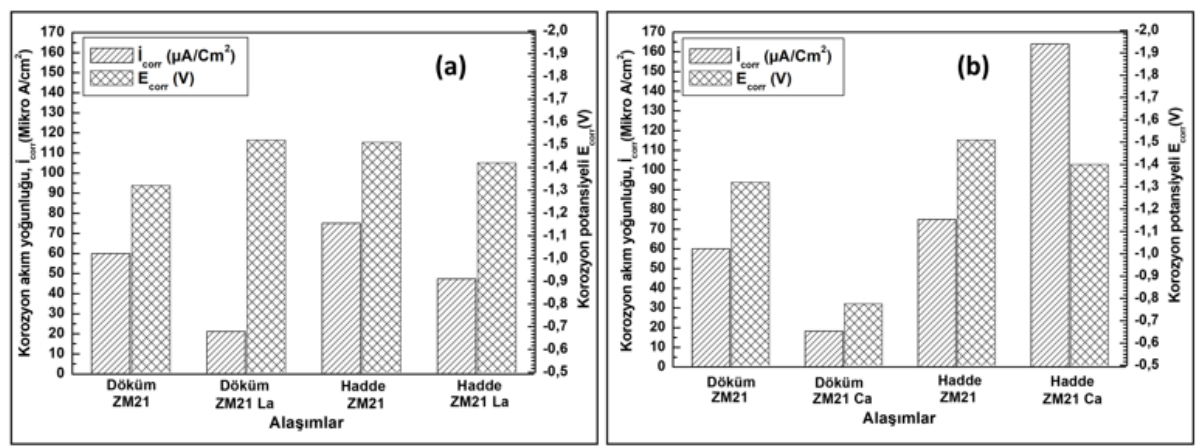

Şekil 8. ZM21 alaşımı ile karşılaştırmalı olarak (a) La ilaveli ve (b) Ca ilaveli alaşımların korozyon akım yoğunlukları (i $\dot{I}_{\text {kor }}$ ve korozyon potansiyelleri $\left(\mathrm{E}_{\mathrm{kor}}\right)$ gösterilmektedir.

\section{SONUÇLAR}

Döküm ve sonrasında haddeleme ile üretilen ZM21, ZM21+0,5(La), ZM21+0,5(Ca) alaşımlarının mikroyapı, mekanik özellikleri ve korozyon davranışlarının karşılaştırılması sonuçları aşağıdaki gibi özetlenebilir: Mikroyapı sonuçları incelendiğinde haddelenmeden sonra tane boyutu incelmiş ve hadde yönünde kesme bantları olduğu düşünülen izler meydana geldiği görülmüştür. SEM, EDX sonuçları incelendiğinde haddeleme sonrası La ilavesiyle fazların uzadı $\breve{g}$, Ca ilavesi ile oluşan sert fazların kesildiği SEM resimlerinde görülmektedir. XRD sonuçları incelenen alaşımların mikro yapılarında her iki alaşımda da $\mathrm{Mg}, \mathrm{MgZn}, \mathrm{MgZn} 2, \mathrm{MgZn}_{3}$ fazları, Ca içeriği ile $\mathrm{C}_{5} \mathrm{Zn}_{3}, \mathrm{Ca}_{2} \mathrm{Mg}_{6} \mathrm{Zn}_{3}$ fazları ve $\mathrm{La}$ içeriği ile $\mathrm{LaZn}_{2}, \mathrm{LaMg}_{3}$ ikili fazlarının oluşumu tespit edilmiştir. Döküm halindeki numunelerin çekme test sonuçları incelendiğinde ZM21'e göre La ve Ca ilaveli alaşımların mekanik özellikleri çok az daha düşük değerlere sahiptir. Ayrıca Ca ilaveli döküm alaşımın \% uzama değeri çok düşüktür. ZM21+0,5(La) Mg alaşımının hem döküm hem de hadde olarak ZM21 Mg alaşımına kıyasla korozyon deneyi sonrasında daha az ağılık kaybı yaşadığı tespit edilmiştir. ZM21 Mg alaşımına kıyasla ZM21+0,5(Ca) alaşımı incelendiğinde döküm olarak daha düşük fakat hadde olarak çok daha fazla ağırlık kaybı yaşadığı tespit edilmiştir. Potansiyodinamik polarizasyon test sonrası ZM21+0,5( $\mathrm{La})$ ve ZM21+0,5(Ca) kalite döküm alaşımlarının ZM21'e 
göre korozyon akım yoğunluğu azalmıştır ve bu da korozyon direncinin arttığı anlamına gelmektedir. Hadde ZM21+0,5(Ca) alaşımının korozyon akım yoğunluğu artmış dolayısıyla korozyon direnci düşmüştür.

\section{TEŞEKKÜR}

Bu çalı̧̧ma Proje No: FDK-2019-2103 numaralı proje ile Karabük Üniversitesi Bilimsel Araştırma Projeleri Koordinasyon Birimi tarafindan desteklenmektedir.

\section{KAYNAKLAR}

[1] Ünal, M., Gören, H. A., Koç, E., Türen, Y., Ahlatç1, H., \& Sun, Y. (2017). Effect of cooling rate and 2 wt \% silicon addition on microstructure and mechanical properties of AZ91 Mg alloys. International Journal of Mechanical and Production Engineering, 5 (7), 25-28.

[2] Mordike, B. L. \& Ebert, T. (2001). Magnesium: properties application-potential. Materials Science and Engineering: A, 302, 37-45.

[3] Ballam, L.R., Arab, H., Bestetti, M., Franz, S., Masi, G., Sola, R., Donati, L., \& Martini, C. ( 2021). Improving the corrosion resistance of wrought ZM21 magnesium alloys by plasma electrolytic oxidation and powder coating. Materials. 14, 2268.

[4] Zhang, E., Yin, D., Xu, L., Yang, L. \& Yang, K. (2009). Microstructure, mechanical and corrosion properties and biocompatibility of $\mathrm{Mg}-\mathrm{Zn}-\mathrm{Mn}$ alloys for biomedical application. Materials Science and Engineering: C, 29, 987-993.

[5] Sriraman, N. \& Kumaran, S. (2019). Improved bio-acceptability of thermomechanically processed ZM21 magnesium alloy. Materials Research Express, 6 (5).

[6] Li, Q., Fan, S., Peng, J., Yang, J., Jiang, X. \& Pan, F. (2014). Effects of Ce on microstructure and mechanical properties of ZM21 magnesium alloy. Materials Research Innovations, 18 (4), 178-182.

[7] Thirumurugan, M., Kumaran, S., Suwas, S. \& Rao T. S. (2011). Effect of rolling temperature and reduction in thickness on microstructure and mechanical properties of ZM21 magnesium alloy and its subsequent annealing treatment. Materials Science and Engineering: A, 528 (29-30), 8460-8468.

[8] Zengin H. \& Türen Y. (2018). Effect of La content and extrusion temperature on microstructure, texture and mechanical properties of Mg-Zn-Zr magnesium alloy. Materials Chemistry and Physics, 214, 421-430.

[9] Xie, Y. P., Wang, Z. Y., \& Hou Z. F. (2013). The phase stability and elastic properties of $\mathrm{MgZn}_{2}$ and $\mathrm{Mg}_{4} \mathrm{Zn}_{7}$ in $\mathrm{Mg}-\mathrm{Zn}$ alloys. Scripta Materialia, 68: 495-498.

[10] Alidoust, M., Kleiven, D. \& Akola, J. (2020). Density functional simulations of pressurized Mg-Zn and AlZn alloys. Physical Review Materials, 4, 4: 045002.

[11] Ghosh, P. \& Medraj, M. (2013). Thermodynamic calculation of the $\mathrm{Mg}-\mathrm{Mn}-\mathrm{Zn}$ and $\mathrm{Mg}-\mathrm{Mn}-\mathrm{Ce}$ systems and re-optimization of their constitutive binaries. Calphad, 41, 89-107.

[12] Alessia, P., Arjun, P., Vitalij, P., Marina, P., Carlo, F., Volodymyr, S., Anja, M. \& Pietro, M. (2018). Effect of chemical and physical pressure on the superconducting properties of $\mathrm{LaZn}_{2}-\mathrm{xSn}_{2}$ ", APS March Meeting 12.

[13] Wang, M. H., Pan, R. K., Li, P. B., Bian, N., Tang, B.Y., Peng, L. M. \& Ding, W. J. (2014). First-principles study on mechanical properties of $\mathrm{LaMg}_{3}$ and $\mathrm{LaCuMg}_{2}$. Journal of Central South University., 21(6), 21362142.

[14] Sreejith, S. S., Mohan, N. \& Kurup, M. R. P. (2018). Experimental and theoretical analysis of a rare nitrato bridged $3 \mathrm{~d}-4 \mathrm{f}$ complex containing $\mathrm{LaZn}_{2}$ core synthesized from a $\mathrm{Zn}$ (II) metallolig and. Journal of Molecular Structure, 1153, 85-95.

[15] Fu, J., Liu, K., Du, W., Wang, Z., Li, S. \& Du, X. (2017). Microstructure and mechanical properties of the as-cast Mg-Zn-Mn-Ca alloys. IOP Conference Series Materials Science and Engineering, 182, 012053.

[16] Gao, L., Yan, H., Luo, J., Luo, A. A. \& Chen R. (2013). Microstructure and mechanical properties of a high ductility Mg-Zn-Mn-Ce magnesium alloy. Journal of Magnesium and Alloys, 1(4), 283-291.

[17] Chen, Z. H., Zhou, T., Chen, D., Yan, H. G., \& Chen, J. H. (2008). Microstructure characterisation and mechanical properties of rapidly solidified $\mathrm{Mg}-\mathrm{Zn}-\mathrm{Ca}$ alloys with $\mathrm{Ce}$ addition. Materials Science and Technology, 24(7), 848-855.

[18] Candan, S., Unal, M., Koc, E., Turen, Y. \& Candan, E. (2011). Effects of titanium addition on mechanical and corrosion behaviours of AZ91 magnesium alloy. Journal of Alloys and Compounds, 509 (5), 1958-1963.

[19] Yang, J., Peng, J., Li, M., Nyberg, E. A. \& Pan, F.S. (2017). Effects of Ca Addition on the Mechanical Properties and Corrosion Behavior of ZM21 Wrought Alloys. Acta Metallurgica Sinica, 30(1) 53-65. 